Article

\title{
How the Economic and Financial Situation of the Community Affects Sport Clubs' Resources: Evidence from Multi-Level Models
}

\author{
Pamela Wicker* and Christoph Breuer \\ Department of Sport Economics and Sport Management, German Sport University Cologne/Am \\ Sportpark Muengersdorf 6, Cologne 50933, Germany; E-Mail: breuer@dshs-koeln.de \\ * Author to whom correspondence should be addressed; E-Mail: p.wicker@dshs-koeln.de; \\ Tel.: +49-221-4982-6107; Fax: +49-221-4982-8144.
}

Academic Editor: Brian P. Soebbing

Received: 24 November 2014 / Accepted: 9 February 2015 / Published: 13 February 2015

\begin{abstract}
In many Western countries, local community sport clubs are important providers of leisure, sport, and social programs. These sport clubs are nonprofit organizations, which operate in an increasingly challenging environment. This study considers a club's direct local environment, i.e., the community the club is located in. The open systems model and the resource dependence represent the theoretical framework. The purpose of this research is to examine the effect of the financial and economic environment in the community on the resource situation of sport clubs (human, infrastructure, and financial resources). The empirical evaluation is undertaken using data from a nationwide survey of non-profit sport clubs in Germany (organizational level; $n=19,345$ ), which are combined with secondary data on community characteristics (community level; $n=3153$ ). Given the hierarchical data structure, multi-level analyses are applied. The results show that volunteer problems are smaller among clubs in communities with high unemployment. Facility and financial problems are greater in large communities. Sport clubs located in communities that could break even were also more likely to break even themselves. The findings show that resource problems are not necessarily due to poor club management, since higher-level (community) factors significantly affect the resource situation of sport clubs too.
\end{abstract}

Keywords: Environment; community; finance; nonprofit sport club; multi-level analysis; resources 


\section{Introduction}

In many Western countries, local community sport clubs are important providers of leisure, sport, and social programs (e.g., [1-3]). Members join the club and pay a membership fee, which allows them to use all programs of the club. By their legal form, these sport clubs are nonprofit organizations. Recent research shows that these organizations operate in an increasingly challenging environment [4], which may impact their functioning. Following Foster and Meinhard [5] "the environment plays a significant role in the creation and survival of organizations” (p. 44). External influences can relate to the political environment (e.g., changes in policies and public funding), but also to the economic environment [6]. Generally, the research focus has been on the social-political environment and the relationship with the government, and how this affects the behavior, structure, and development of non-profit organizations $[7,8]$. However, the environment of a non-profit organization includes more than the government and funding relationships [9].

For many non-profits operating at a local level, the community the organization is located in represents the direct environment. Within the community, the economic and financial situation is critical to the organization [6]. Specifically, the labor market situation and resulting income distribution of the population may be critical for membership based non-profit organizations. In communities with high unemployment rates and low income, residents may not have the resources to become a member. Moreover, the labor market situation affects the financial situation of the community's government in the sense that it has high social spending while generating low revenues from income taxes. When the community has financial difficulties, its support of local non-profit organizations in terms of providing financial or infrastructure resources may be limited. However, not much is known about community effects on non-profit resources.

The purpose of this study is to examine the effects of the financial and the economic situation in the community on organizational resources of local non-profit organizations. The research context for this examination is the non-profit sport club sector in Germany. Human, infrastructure, and financial resources are the focus of this research [10]. Although German sport clubs have more members and provide programs in more sports compared with clubs in other countries, they report similar challenges in terms of human, infrastructure, and financial resources [1-3]. The aim of this study is to analyze how external community-related factors influence these resources since intra-organizational factors have already been examined in previous research [11]. In doing so, this study advances the following main research question: How do community factors affect organizational resources of non-profit sport clubs?

When examining the relationship between nonprofits and their environment, it must be considered that this relationship has a multi-level structure [12], which has methodological implications. There are two levels in this study, the community level and the organizational level (sport clubs). These levels are hierarchical in nature, i.e., sport clubs are nested within communities and clubs in the same community share the same community characteristics. This hierarchical structure must be considered in empirical examinations by using multi-level analyses, which represent the appropriate method [13]. Thus, this study contributes to the body of research on the relationship between non-profits and their environment by applying multi-level analyses, which have largely been neglected in non-profit research with a few exceptions (e.g., [14]). 


\section{Theoretical Framework and Literature Review}

\subsection{Open Systems Perspective and Resource Dependence Theory}

At least two theoretical approaches are relevant to frame the proposed research; the open systems model [15] and the resource dependence theory [16]. Following Scott [15], organizations can be regarded as rational, natural, or open systems. While the first two systems relate more to intra-organizational aspects, the last perspective is critical when examining the relationship between organizational behavior and the external environment. Organizations should be seen as open systems whose performance is the result of interchanges between the organization and its environment $[15,17]$. Since no organization disposes of all the resources it needs for survival, all organizations are in an exchange with their environment to some extent [15]. Therefore, it is important to understand the context in which the organization operates.

The resource dependence theory (RDT) [16] is rooted in the open systems perspective [15]. Following this theory, organizations seek scarce resources from external stakeholders in the environment [16]. Typically, organizations do not have all the resources they need for their operations; they are incomplete systems [17]. Therefore, they compete for scarce resources in their environment [7]. However, organizations may lose autonomy when external stakeholders exert power and control over the organization as a result of resource dependence [16]. In summary, organizations depend on their environment for acquiring resources, seeking legitimacy, and guaranteeing survival [15]. In the present research, the type of external environment which is considered is the local community; i.e., the municipality where the sport club is located.

Following Oliver [18], this need for external resources is one of the determinants of inter-organizational relationships. This determinant is referred to as necessity-the others are asymmetry, reciprocity, efficiency, stability, and legitimacy. She further states that relationships driven by necessity can be voluntary or mandatory in nature. In the present research context where the community represents the direct environment, the relationships can be considered mandatory. Although a sport club can be founded wherever the founding members wish to, it must be located in a community. Typically, clubs are founded in communities where the founding members live. Thus, the external environment cannot be voluntarily chosen. Yet, it is likely that the perceptions of the mandatory environment are reduced by organizations [19]. For this reason, it is important to sharpen perceptions by examining potential influences of this environment on organizations.

Importantly, the exchange between the organization and its environment is not restricted to resources. In addition to resource inputs from the environment, organizations also try to secure legitimacy and provide outputs to various stakeholders such as members, clients, and the general public [15]. Both aspects-resource inputs and the provision of organizational outputs to various stakeholders including potential members and customers-are critical in the present research.

While the assumed relationships between organizations and their environment within RDT are widely accepted, it was pointed out that the proposed relationships should be tested more rigorously in empirical studies [20]. Although it is not possible to empirically test RDT in its entirety, it was widely analyzed as summarized by Nienhueser [21]. Yet, this summary also indicates that most studies looked 
at for-profit organizations. This study adds to the body of literature on RDT by examining non-profit sport clubs.

\subsection{Research on Nonprofit Organizations and the Environment}

The influence of the environment on organizational behavior has been examined to a lesser extent than intra-organizational dimensions [17]. Specifically, the body of research on the effects of community factors is relatively scant. Since non-profits are strongly linked with government authorities, probably more than with any other type of institution [8], the majority of studies looked at the link between the government and the non-profit organization (e.g., [8,22,23]). One reason for the neglect of other external factors could be the availability of adequate data and measures. Oftentimes, the share of government income is used as a measure to proxy government influence [22,24]. One study used the field of activity, the percentage of funding from various sources, and the presence of a state audit requirement as measures for external environmental characteristics [9]. However, these characteristics do not seem to be characteristics of the external environment; instead these are internal characteristics that are influenced by the environment. This example illustrates the methodological difficulties associated with an examination of environmental factors.

In summary, several studies analyzed the relationship between non-profit organizations and the external environment. Nevertheless, some shortcomings can be observed. First, most studies focused on the political environment and specifically the government as an external entity (e.g., [23]). Yet, the economic and financial environment is also important and should not be omitted [6]. Probably due to issues regarding data availability, economic and financial factors have been largely neglected in previous research. Second, most studies were qualitative in nature (e.g., [17,25,26]), while the chosen measures on the community level could be improved in quantitative approaches [9]. Therefore, the body of research would benefit from quantitative studies that apply adequate measures and allow generalizations and predictions. Third, community measures have not been adequately integrated into statistical analyses; they were treated like characteristics on the organizational level [11,27]. As will be seen in the data analysis section, the multi-level analysis is the appropriate statistical test in the case of hierarchical (nested) data. This study attempts to address these shortcomings.

\subsection{Community-Level Effects on Organizational Resources of Sport Clubs}

This study extends the perspective of previous research and considers the economic and financial environment. Based on the open systems model [15] and the resource dependence theory [16] it is assumed that organizational resources of non-profit sport clubs are affected by the environment. In the next paragraphs, it is explained what community factors may be relevant to organizational resources and how they could potentially affect those resources. Yet, it is difficult to find related studies because research looking at the role of community factors is relatively scarce.

First of all, the size of the community is associated with the resources of sport clubs, specifically human and financial resources. The community size is relevant when looking at organizational outputs such as programs and services that are provided to a variety of external stakeholders (e.g., donors, corporate sponsors, customers participating in sports courses). While club members are obvious stakeholders, also customers (non-members), donors, and the wider community such as businesses 
engaged as sponsors may be interested in the clubs' services. For example, some clubs also offer sport courses for non-members against a service fee [28], while corporate businesses may be interested in showcasing social corporate responsibility by sponsoring and supporting local sport clubs. From the output perspective sport clubs may have more opportunities to provide their services in larger communities, simply because more potential stakeholders are present.

However, it could also be argued that there is more competition for resources in large communities because there are also more clubs and other fundable organizations and, thus, stakeholders have different opportunities to spend their money on. Since environmental resources are often limited, there is competition among organizations for scarce resources [26]. The level of competition increases with an increasing number of competitors and is thus higher in large communities [28]. To successfully compete for scarce resources, organizations may feel more pressure to adapt programs to the preferences of stakeholders in an effort to please more stakeholders [25]. This change in programs may in turn negatively affect potential members and volunteers working for the club.

The few studies analyzing effects of community size showed mixed findings. In a study on Finnish sport clubs, Koski [11] detected a negative correlation between town size and organizational effectiveness: Clubs in larger communities were less effective. A German sport club study [27] revealed that clubs in larger communities had significantly greater financial problems, while the effect of community size on problems related to members and volunteers was not significant. A different German study [28] showed that clubs in larger communities charge higher membership fees, which may be a result of the evident higher competition in large communities. The clubs receive less support from the community and have to charge their members higher fees to compensate for missing income in other areas. The study also showed that problems regarding infrastructure resources (sport facilities) are bigger for clubs in large communities. Given the above evidence, it is assumed that clubs located in large communities experience greater resource problems.

Second, the financial environment is relevant for the sport clubs' resource situation. While the focus of previous research was on the effect of public funding on aspects like program design [25] and organizational autonomy [23], this research looks at the financial situation of the community, which is critical for the support of sport clubs. Research showed that organizational performance is affected by environmental resources [17], specifically financial resources [26]. This also applies to the sport club sector [29].

The community's financial situation is particularly relevant for infrastructure resources (like investments in public sport facilities that can be used by clubs) and for direct financial support. Clubs located in communities with financial difficulties should be less likely to receive public funding, because expenditure on culture and sport are typically cut in case of financial difficulties [30]. The reality is that many German communities have debts and are far away from breaking even at the end of the financial year [31]. The community's financial difficulties are mirrored in the public funds provided to clubs: Only approximately half of the clubs in Germany receive funds from the community [28]. Based on the above explanations, it can be assumed that the better the financial situation of the community, the smaller the resource related problems of sport clubs.

Third, the economic environment affects the resource situation of sport clubs. The focus of this research is on the employment and income situation of the local population. Recent evidence documents that the labor market situation and the resulting income distribution of the population is 
problematic in many countries [32]. Although the unemployment rate and income disparity are lower in Germany than in other countries [32], there are nevertheless many people who are working full-time, but still receive low wages. In 2010, 23\% of the employed people received low wages and therefore needed additional money from the employment office as compensation [33].

The employment and income situation should be important for human, financial, and infrastructure resources of sport clubs. The income situation of the resident population is associated with the community's financial position; the higher the income of the resident population, the higher the revenues the community generates from income taxes. Those revenues should improve the community's financial situation and capacity to financially support clubs and invest in public sport facilities. Thus, economic and financial aspects are interrelated. The relationship between the employment situation and human resources (i.e., volunteers) is probably the topic that has received most academic attention. Andreff [34] conceptualized that there is a possible relationship between unemployment and voluntary work. He recommended that unemployment could be reduced when sport organizations replace voluntary labor by paid labor. Following his idea, high unemployment would lead to volunteer problems because volunteers are replaced by paid staff. However, it is also likely that in this case clubs would not perceive a shortage of volunteers because all tasks are completed.

When examining the relationship between employment and voluntary work, the opportunity costs of time must be considered. Opportunity costs refer to the income people forego by spending time on other activities (e.g., volunteering) rather than work [35]. Following the opportunity cost approach [35], unemployed people have zero opportunity costs (when a pure approach is considered) and should be more likely to volunteer because opportunity costs are lower. On the other hand, employed people have higher opportunity costs and are, therefore, expected to be less likely to volunteer. These arguments were supported in previous research documenting a negative relationship between working time and volunteering: individuals working full-time were less likely to volunteer than individuals without employment or those only working part-time [36,37]. However, once the decision to volunteer was positive, full-time work was positively associated with volunteering hours, i.e., individuals working full-time were volunteering more hours [36]. Another study also showed that volunteers are typically highly skilled [38]. Although these findings may look contradictory, Freeman [38] argued that people with high opportunity costs of volunteering carefully reflect their decision to volunteer and only volunteer when asked to do so. Taking the arguments of the opportunity cost approach into account, volunteer problems should be smaller for sport clubs located in communities with high unemployment. The effects of community factors are examined empirically using comprehensive sport club data from Germany.

\section{Method}

\subsection{Data Sources}

A combination of primary data (organizational level; sport clubs) and secondary data (community level) is used for this research. Primary data were collected with a nationwide online survey of German non-profit sport clubs in 2009. The clubs' email addresses were provided by the state sports confederations; altogether 63,468 email addresses of a total of approximately 91,000 clubs were made 
available. All clubs with a valid email address received an invitation email including a personalized link to the online questionnaire that allows logging in and out. After controlling for drop-outs (5399), 58,069 clubs were invited to take part in the survey. The survey was online from October to December 2009 with $n=19,345$ clubs participating (response rate: 33.3\%). The sample is representative for German sport clubs in terms of size and state. Since 2009, the year of the data collection, no major changes were observed in the German sport club system.

In a second step, secondary data on the characteristics of communities were made available. The Federal and Regional Statistical Offices release those data every year, but the included variables are inconsistent. While community size is always included, figures on unemployment and the community's finances (e.g., tax income) are not available in all years. For 2008, most community figures are available. The club survey is part of a wider sport club project where data are collected every two years since 2005 [28]; however, due to the restricted availability of data on the community level, the third wave from 2009 was used for the analysis since the financial and membership data from the club survey refer to the year before the survey (because 2008 is the last completed household year). The secondary data include information about all communities in Germany [39]. They are provided with community codes. Based on the postcode and the club's community name the respective community code was assigned to every club in the primary dataset. Clubs from the same community received the same community code. Altogether, the clubs in the sample are located in $n=3153$ different communities. The community code is the key variable that links both datasets.

\subsection{Measures and Variables}

The variables used in this study are summarized in Table 1, the descriptive statistics are provided in Table 2. Human, infrastructure, and financial resources of sport clubs are examined and operationalized with five variables. Four variables capture the perceived severity of organizational problems related to those resources. These are the recruitment and retention of (1) members (P_MEM) and (2) volunteers (P_VOL); (3) the availability of sport facilities (P_FAC); and (4) the financial situation of the club (P_FIN). In sport club research it is common to ask for problems or challenges (e.g., [1-3]). Also, the subjective problem items are not biased by club size like other potential resource measures. The financial resources are enriched with one objective measure capturing whether the club could at least break even at the end of the financial year (BREAKEVEN_O). These five variables serve as the dependent variables in the models.

Independent variables are available on two levels (Table 1). The community level variables are community size (SIZE), which proxies market size and the level of competition for resources as explained in the theoretical part. BREAKEVEN_C captures the financial situation of the community. The profit of the community could have also been used in the analysis; yet, local governments are non-profit organizations and thus a profit measure is not adequate given that they are only required to break even. The economic environment is captured with two variables. The labor market situation is covered with UNEMP, which is obtained by dividing the number of unemployed people by the number of inhabitants in the community. Figures on the potential total work force, which is normally used for the calculation of the unemployment rate, are not available. LN INC_TAX reflects the income situation in the community and is also adjusted for community size. Another opportunity would be to 
use income from business taxes; however, these variables are highly correlated $(r=0.989 ; p<0.001)$ causing multicollinearity problems in the models. We decided to use the income tax variable because most communities generate revenue from income taxes, while there are some (particularly smaller) communities, which do not generate revenue from business taxes, as they do not have any corporate businesses. Therefore, the business tax variable is excluded from the analysis.

Table 1. Overview of variables.

\begin{tabular}{|c|c|c|}
\hline Variable & Description & Scale \\
\hline & Dependent variables & \\
\hline P_MEM & Recruitment/retention of members ( 1 = no problem, 5 = a very big problem $)$ & Ordinal \\
\hline P_VOL & Recruitment/retention of volunteers ( 1 = no problem, 5 = a very big problem $)$ & Ordinal \\
\hline P_FAC & Availability of sport facilities ( 1 = no problem, 5 = a very big problem) & Ordinal \\
\hline P_FIN & Financial situation of the club (1 = no problem, 5 = a very big problem $)$ & Ordinal \\
\hline BREAKEVEN_O & $\begin{array}{l}\text { Club could at least break even (=total revenues-total expenses } \geq 0 ; 1=\text { yes) } \\
\text { Independent variables: Community level }\end{array}$ & Dummy \\
\hline SIZE & Community size (=number of inhabitants in the community/1000) & Metric \\
\hline BREAKEVEN_C & Community could at least break even (=total revenues-total expenses $\geq 0 ; 1=$ yes) & Dummy \\
\hline UNEMP & Unemployment (=number of unemployed people/number of inhabitants) & Metric \\
\hline LN INC_TAX & $\begin{array}{l}\text { Logged per capita revenues from income taxes } \\
\text { Independent variables: Organizational level }\end{array}$ & Metric \\
\hline MEMBERS & Number of members in the club & Metric \\
\hline VOL_ENG & $\begin{array}{l}\text { Share of voluntary engagement in \% (=number of core volunteers/number of } \\
\text { members } \times 100)\end{array}$ & Metric \\
\hline SEC_VOL & Share of secondary volunteers (in \%) & Metric \\
\hline PAID_STAFF & Club has paid staff $(1=$ yes $)$ & Dummy \\
\hline PUB_FAC & Club uses public sport facilities (1 = yes) & Dummy \\
\hline OWN_FAC & Club possesses its own sport facilities $(1=$ yes $)$ & Dummy \\
\hline STRATEGY & Our club has a strategy (from 1 = do not agree at all, 5 = totally agree) & Ordinal \\
\hline
\end{tabular}

Table 2. Descriptive statistics.

\begin{tabular}{ccc}
\hline & Mean & SD \\
\hline Prganizational Level & \\
P_MEM & 2.70 & 1.16 \\
P_VOL & 3.14 & 1.20 \\
P_FAC & 2.22 & 1.36 \\
PREAKEIN & 2.27 & 1.19 \\
MEMBERS & 0.63 & 0.48 \\
VOL_ENG & 394.44 & 1546.01 \\
SEC_VOL & 12.47 & 23.91 \\
PAID_STAFF & 23.74 & 22.21 \\
PUB_FAC & 0.38 & 0.49 \\
OWN_FAC & 0.59 & 0.49 \\
STRATEGY & 0.55 & 0.50 \\
SIZE & 3.56 & 1.06 \\
BREAKEVEN_C & 0.51 & \\
UNEMP & 0.04 & 0.50 \\
LN INC_TAX & 0.00 & 0.01 \\
\hline
\end{tabular}


On the organizational level, this study controls for the organizational capacity of sport clubs that may also affect resource problems [27]. These are MEMBERS capturing club size, VOL_ENG measuring the share of core volunteers (i.e., those with a formal position), SEC_VOL measuring the share of secondary volunteers (i.e., those who only help sporadically in the club), and PAID_STAFF reflecting whether the club employs paid staff. PUB_FAC captures whether the club uses public sport facilities (that are provided by the community) and OWN_FAC whether the club possesses its own facilities (including a club house). These variables capture the two main types of facilities German sport clubs rely upon. Hiring or leasing facilities from other stakeholders like a private operator, a trust or charity, and a church are less relevant in Germany compared with the UK [3]. Importantly these are not two categories of the same variable. It is likely that some clubs use both public facilities (in Germany, school sport facilities are also owned by the community and are, thus, public facilities) and their own facilities, while there may be other clubs, which do not rely on any type of facility at all (e.g., in road cycling clubs, members may train on the street). STRATEGY is a measure for the club's planning and development capacity, which was found to influence the perceived severity of organizational problems [27]. The independent variables on the organizational level serve as controls and are not the focus of this research.

\subsection{Statistical Analysis: The Multi-Level Analysis}

For the statistical analysis the hierarchical (or nested) structure of the data must be considered, i.e., sport clubs are nested within communities. Thus, sport clubs located in the same community share the same community-level characteristics. The adequate statistical procedure to analyze hierarchical (nested) data is the multi-level analysis (also referred to as hierarchical linear model; HLM). Following Tabachnick and Fidell [40], "analyzing data organized into hierarchies as if they are all on the same level leads to both interpretational and statistical errors". One of the common errors of interpretation is referred to as the ecological fallacy, i.e., applying higher-level results to the lower level [40].

Multi-level analyses require two different datasets because the number of cases differs between the levels. If this is not the case, another misleading interpretation occurs referred to as the atomistic fallacy, i.e., lower-level analyses are interpreted at the higher (group) level [41]. Applied to this research, multi-level models allow predictions of club parameters adjusted for community scores and predictions of community scores adjusted for club differences within communities. When higher-level variables are simply included in the lower-level dataset and treated as lower-level variables in the analyses, the degrees of freedom are too high leading to an inflated Type I error [40]. As a result of the nested structure there are fewer cases on the higher level, i.e., several clubs are located in one community. In some communities there is only one club in the data; this is not problematic as long as there are communities with more clubs [42]. The two levels are linked in the analysis with the key variable, community code. The different levels are mirrored in the equations which, consequently, have two-sub-indexes ( $i$ for organizational level and $j$ for community level). In line with Todd et al. [43], the initial model in this study is in the form of a general linear model:

$$
Y_{i j}=\beta_{0 j}+\beta_{1 j} X O_{i j}+r_{i j}
$$


where $\mathrm{Y}_{\mathrm{ij}}$ is the outcome of interest for club $i$ in community $j ; \beta_{0 j}$ the intercept for each community; $\beta_{1 j}$ the expected change in the outcome of interest $\left(\mathrm{Y}_{\mathrm{ij}}\right)$ with a one-unit increase in $\mathrm{XO}_{i j}$; and $r_{i j}$ the residual.

Within multi-level analysis, every organizational-level estimate is calculated in separate community-level equations, which are of the following form:

$$
\begin{aligned}
& \beta_{0 j}=\gamma_{00}+\gamma_{01} X_{j}+u_{0 j} \\
& \beta_{1 j}=\gamma_{10}+\gamma_{11} X_{j}+u_{1 j}
\end{aligned}
$$

where $\beta_{0 j}$ is the intercept from the organizational-level equation; $\beta_{1 j}$ the slope; $\mathrm{XC}_{j}$ the community-level variable; $\gamma_{00}$ and $\gamma_{10}$ the community-level intercepts; $\gamma_{01}$ and $\gamma_{11}$ the community-level slopes; and $u_{0 j}$ and $u_{1 j}$ the community-level residuals. The community-level Equations (2) and (3) can be substituted into the organizational-level Equation (1) yielding the multi-level model.

Altogether, five multi-level models are estimated. A hierarchical non-linear model is run for the dependent dummy variable BREAKEVEN_O, while hierarchical linear models are estimated for the organizational problems. The four problem variables are assessed on five-point Likert scales. Following Wittenberg and Cramer [44], an ordinal variable with at least five categories can be treated as a metric variable when the interval distances are similar (which is the case in Likert scales). Bortz [45] states that when these requirements are given, all statistical tests for metric variables can be applied in research practice. All independent variables from Table 1 are entered in the models. Fixed-effects models are preferred because they provide the constant for all groups (communities). Models with robust standard errors are estimated [46]. Other specifications of the multi-level models (e.g., least-squares estimates, models without robust standard errors) were tried, but the results were not materially different.

The analyses are performed using specific multi-level software (HLM 7.1) [47].

Multi-level models require large sample sizes, particularly on the higher level (here: community level). Following Tabachnick and Fidell [40], at least 20 cases should be available on this level. Multi-level analyses were only rarely applied in non-profit research [14,37]. One likely reason for this shortcoming could be the need for many higher level units combined with the lack of available data at that higher level. The present study is based on 3,153 higher-level units and, thus, meets the required sample size [40].

\section{Multi-Level Results and Discussion}

The results of the multi-level models for resource problems of sport clubs are summarized in Table 3. Since the focus of this study is on community-level effects, no attention is paid to organizational-level factors in the discussion of results, also because they have already been discussed in previous research $[27,48]$. Regarding human resources, only unemployment has a significant effect on the dependent variable in model 1: The higher the unemployment in the community, the bigger the organizational problem of recruiting and retaining members. This finding can be explained by the costs associated with club participation and the income needed for club membership. Although sport clubs charge relatively low membership fees compared with commercial sport providers like fitness centers [28], income is a positive driver of club membership [49] and unemployed people may not have the financial resources to afford club membership. Consequently, clubs in communities with high unemployment experience problems of recruiting members. 
Table 3. Results of the multi-level analyses for organizational problems regarding human and infrastructure resources.

\begin{tabular}{|c|c|c|c|c|c|c|}
\hline & \multicolumn{2}{|c|}{ Model 1: P_MEM } & \multicolumn{2}{|c|}{ Model 2: P_VOL } & \multicolumn{2}{|c|}{ Model 3: P_FAC } \\
\hline & icient & $t$ & Coefficient & $t$ & Coefficient & $t$ \\
\hline \multicolumn{7}{|c|}{ Community Level } \\
\hline Constant & 3.660791 & $45.082 * * *$ & 3.930460 & $51.574 * * *$ & 2.091705 & $24.328 * * *$ \\
\hline SIZE & 0.000124 & 1.015 & 0.000052 & 0.658 & 0.000468 & $4.289 * * *$ \\
\hline BREAKEVEN_C & 0.002454 & 0.076 & -0.044889 & -1.456 & -0.000975 & -0.029 \\
\hline UNEMP & 2.198204 & $2.416 * *$ & -1.545328 & $-1.898 *$ & -1.671486 & $-1.902 *$ \\
\hline LN INC_TAX & 0.484344 & 0.146 & 6.631643 & 1.609 & -6.880648 & $-1.748 *$ \\
\hline \multicolumn{7}{|c|}{ Organizational Level } \\
\hline MEMBERS & -0.000036 & $-1.752 *$ & -0.000015 & $-3.641 * * *$ & 0.000018 & 0.581 \\
\hline VOL_ENG & 0.003547 & $1.964 * *$ & -0.001669 & $-1.837 *$ & -0.000536 & -0.899 \\
\hline SEC_VOL & -0.002985 & $-3.725 * * *$ & -0.009652 & $-13.269 * * *$ & -0.004131 & $-5.248 * * *$ \\
\hline PAID_STAFF & -0.075336 & $-2.345 * *$ & 0.119982 & $3.576 * * *$ & 0.153535 & $3.802 * * *$ \\
\hline PUB_FAC & -0.263328 & $-7.482 * * *$ & 0.146998 & $4.333 * * *$ & 0.741956 & $18.814 * * *$ \\
\hline OWN_FAC & -0.024832 & -0.746 & 0.246436 & $7.586 * * *$ & -0.462229 & $-11.691 * * *$ \\
\hline STRATEGY & -0.224910 & $-14.505 * * *$ & -0.203595 & $-12.867 * * *$ & 0.004163 & 0.248 \\
\hline$R_{\text {comm. level }}^{2}$ & 0.058 & & 0.111 & & 0.162 & \\
\hline$R_{\text {org. level }}^{2}$ & 0.058 & & 0.111 & & 0.162 & \\
\hline
\end{tabular}

${ }^{*} p<0.1 ;{ }^{* *} p<0.05 ;{ }^{* * *} p<0.01$; displayed are the unstandardized coefficients; robust standard errors reported.

Model 2 shows that unemployment has a significant negative effect on the problem of recruiting and retaining volunteers. Thus, the finding is in accordance with the literature conceptualizing a relationship between unemployment and voluntary work [34]. However, this study is among the first to provide empirical evidence of this relationship using data on the organizational and community level since previous research was limited to the individual level and identified drivers of individual volunteering [36]. The negative effect implies that the higher the unemployment in the community, the smaller are volunteer problems among clubs. This negative effect is in line with the opportunity cost approach suggesting that the opportunity costs of time are lower for unemployed people, which is why those people should be more likely to volunteer $[35,38]$. Consequently, clubs in communities with high unemployment can mobilize volunteer resources more effectively.

Concerning infrastructure resources, model 3 shows that the problem related to the availability of sport facilities is significantly determined by community size, unemployment, and revenue from income taxes. The larger the community, the bigger are facility problems. This finding is in line with the previous assumption that competition for scarce resources is higher in large communities because of more competitors. The community provides a limited number of facilities for schools that are also used by clubs in the afternoon and evening hours. Since there are typically more clubs in larger communities, the facilities have to be shared by more clubs leading to increased facility problems.

The results also show that problems related to the availability of sport facilities are smaller in communities with high unemployment and high revenues from income taxes. While high unemployment may lead to fewer club memberships and thus fewer people needing facilities, the effect of revenues from income taxes is more associated with the community's or the local 
government's financial position. Communities that are in a good financial position can afford to invest money in building and maintaining sport facilities which can then be provided to sport clubs, while communities that have financial difficulties spend most of their money on education and child care facilities leaving no money for sport facilities. This situation is not specific to Germany since clubs in other countries also report facility issues [1,3].

Turning to financial resources (Table 4), model 4 reveals that the perceived financial situation of the clubs is worse in large communities with high unemployment. In large communities competition for financial resources from the local government, local businesses, and other stakeholders is higher [28] leaving fewer resources for each club. Also, the potential contribution of individuals is lower when inhabitants are unemployed and, thus, have fewer financial resources at their disposal that can be used for memberships and/or donations.

Table 4. Results of the multi-level analyses for financial resources.

\begin{tabular}{|c|c|c|c|c|}
\hline & \multicolumn{2}{|c|}{ Model 4: P_FIN } & \multicolumn{2}{|c|}{ Model 5: BREAK EVEN_O } \\
\hline & Coefficient & $t$ & Coefficient & $t$ \\
\hline \multicolumn{5}{|c|}{ Community Level } \\
\hline Constant & 2.046551 & $25.576 * * *$ & 0.428219 & $2.288 * *$ \\
\hline SIZE & 0.000255 & $3.214 * * *$ & -0.000236 & -1.084 \\
\hline BREAKEVEN_C & -0.035742 & -1.138 & 0.188273 & $2.447 * *$ \\
\hline UNEMP & 4.819861 & $5.454 * * *$ & -2.446856 & -1.183 \\
\hline INC_TAX & 0.258572 & 0.068 & -4.737284 & -0.478 \\
\hline \multicolumn{5}{|c|}{ Organizational Level } \\
\hline MEMBERS & -0.000014 & $-1.785 *$ & 0.000039 & 0.598 \\
\hline VOL_ENG & 0.000890 & 0.841 & 0.000390 & 0.293 \\
\hline SEC_VOL & -0.000374 & -0.498 & 0.005485 & $3.109 * * *$ \\
\hline PAID_STAFF & 0.173759 & $5.137 * * *$ & -0.051557 & -0.631 \\
\hline PUB_FAC & 0.031933 & 0.957 & -0.015956 & -0.198 \\
\hline OWN_FAC & 0.244443 & $7.152 * * *$ & -0.042499 & -0.546 \\
\hline STRATEGY & -0.066732 & $-4.484 * * *$ & 0.019394 & 0.563 \\
\hline$R^{2}$ comm. level & 0.057 & & 0.170 & \\
\hline$R^{2}$ org. level & 0.057 & & 0.216 & \\
\hline
\end{tabular}

Model 5 analyses the determinants of whether a club could at least break even (BREAKEVEN_O). The only significant community-level factor is whether the community could at least break even. This means that clubs located in communities with solid finances are also more likely to have solid finances. This significant relationship could be a result of the exchange of financial resources between the local government and the sport club in the sense that a financially healthy government is capable to provide more resources for clubs that are then also financially healthier. However, a different explanation can be advanced, too: The community could serve as a role model for clubs, in a positive and negative way. When people running clubs are used to an environment where financial problems 
are common, they are also more likely to run the club in a way that it has financial problems. More generally speaking, people adopt the characteristics, behavior, and attitudes of people in their environment, a phenomenon that is referred to as social contagion [50]. While previous research focused on obesity, smoking, and happiness [50], this phenomenon may also apply to managing financial resources. Altogether, the results showed that not only the mere size of the community is relevant to sport clubs [11,37], but also other community-level factors.

Comparing the community-level effects in Model 4 and Model 5 shows that different variables are significant. Yet, the direction of effects is similar. Recall that negative effects in Model 4 mean that this factor reduces the severity of the problem (which is beneficial), while positive effects in Model 5 indicate that the likelihood of breaking even increases (which is also beneficial). Nevertheless, these differences-although only in the significance of variable-are interesting because both models examine the financial situation. Yet, Model 4 is based on a subjective measure (i.e., the perceived of the problem financial situation of the club) and Model 5 on an objective measure (i.e., whether the club could at least break even; calculated based on the reported revenues and expenditures). Previous research showed that both variables are positively correlated [51]. Thus, it is unlikely that clubs tended to over- or underestimate their financial situation in the subjective judgment. Yet, the scale allows a more nuanced judgment, while the breakeven measure is a dummy variable with less variation.

In summary, the regression results reveal that the $R^{2} \mathrm{~s}$ on the community level are (almost) as high as on the organizational level indicating that community-level factors are equally important for the resource situation of sport clubs. It also stands out that-despite the large sample size on both levels - some variables have no significant effect and some significant effects are based on relatively low $t$-values (e.g., the effect of UNEMP on P_VOL). The difficulty of observing relationships, which are statistically significant and can, thus, be applied to all clubs may be explained by the heterogeneity of German sport clubs in terms of members and volunteers (as evident by the standard deviations in Table 2). The heterogeneity of clubs together with the cross-sectional character of the sample may also explain the relatively low $R^{2} \mathrm{~s}$ - a problem shared by previous research [27].

This study has implications for club management and policy makers. The finding that community factors (as an area of an organization's direct environment) influence organizational resources has implications for the management of non-profit organizations in general and specifically for non-profit sport clubs which are important providers of local leisure and sport programs in many countries (e.g., [1,3]). On the one hand, the findings imply that organizations should not only manage their internal processes, but also take steps to actively engage with their environment [6]. One form of managing the financial environment would be advocacy, which was found to be positively correlated with an organization's government income [22]. While the results support previous research stating that governance is critical to the effectiveness of nonprofit sport organizations [52], they also draw attention to the importance of an organization's environment. Thus, on the other hand, the results indicate that resource problems of sport clubs are not necessarily only due to poor club management, since higher-level effects (here: community factors) significantly affect the resource situation of sport clubs too. In addition to management implications, this study has practical implications for policy makers. The results highlighted that not only the internal, but also the external situation affects the resources of sport clubs and their effective functioning. This has implications for the distribution of public funding: public subsidies may not be effectively directed at sport clubs when the economic and 
financial situation is critical. Policy makers should ensure to also support the communities because a sound economic and financial environment is important to the functioning of sport clubs. This is particularly relevant in Germany where many communities have serious financial debts [53], which inarguably affect the situation of the local sport clubs.

\section{Conclusions}

The environment is important for organizational behavior and the resource situation of non-profits. The focus of this study was on the direct environment of organizations, i.e., the community the organization is located in. Community-level effects on the resources of non-profit organizations were examined using the example of non-profit sport clubs in Germany. This study was among the first to integrate the community level into statistical models using multi-level analyses and to consider the economic and financial environment. The results show that not only community size, but also the financial situation of the community, the level of unemployment, and the revenue from income taxes significantly affect club resources. While these results are not unexpected, this study is among the first to provide quantitative evidence of these relationships. Given that resource problems are similar among sport clubs in other countries [2,3] and that the chosen community-level factors are also relevant to communities and clubs in other countries, the findings of this study should be relevant to sport clubs in other countries and non-profit organizations in other industries.

This study has some limitations that represent avenues for future research. First, this study is only based on cross-sectional data. While panel data would have been available on the organizational level, the availability of community-level data is problematic, specifically when consistent measures are needed over time. Given the evident importance of community-level factors and the limited empirical evidence particularly regarding quantitative approaches, this study calls for more research in this area and the application of multi-level analyses. Future research should also examine how the economic and financial situation of the community affects sport clubs in other countries, which-as noted earlier-share similar problems regarding human, infrastructure, and financial resources [1-3]. Another limitation refers to the measures used on the community level. While it would have been interesting to also examine the effects of other financial and economic indicators like debts, gross domestic product, and the number of potential competitors, this study is restricted to the measures that were available. Third, this study only provides evidence that the environment in the form of the community affects the resources of sport clubs. Future research should examine the power relations between the community and sport clubs, which result from resource dependence and external impacts. Fourth, this study is limited to two levels of analysis. Future research may add another layer like the state level or the individual level (i.e., club members) to the multi-level analysis.

\section{Acknowledgements}

The authors would like to thank the Federal Institute for Sports Sciences (BISp), the German Olympic Sports Confederation (DOSB), and the 16 federal state sports confederations (LSBs) for supporting the research into sport clubs in Germany (Sport Development Report). 


\section{Author Contributions}

Christoph Breuer is the head of the project Sport Development Report from which the sport club data (organizational level) were taken. Pamela Wicker conducted the data analysis and wrote the final manuscript.

\section{Conflicts of Interest}

The authors declare no conflict of interest.

\section{References}

1. Lamprecht, M.; Fischer, A.; Stamm, H.P. Die Schweizer Sportvereine: Strukturen, Leistungen, Herausforderungen [Sport Clubs in Switzerland: Structure, Performance, and Challenges]; Seismo: Zurich, Switzerland, 2012.

2. Lasby, D.; Sperling, J. Understanding the Capacity of Ontario Sports and Recreation Organizations; Imagine Canada: Toronto, ON, Canada, 2007.

3. Sport Recreation Alliance (SRA). Sports Club Survey 2013. Available online: http://www.sportandrecreation.org.uk/policy/SSC (accessed on 12 December 2013).

4. Enjolras, B. A governance-structure approach to voluntary organizations. Nonprof. Volunt. Sect. Quart. 2009, 38, 761-783.

5. Foster, M.K.; Meinhard, A.G. Diversifying revenue sources in Canada. Nonprofit Manag. Lead. 2005, 16, 43-60.

6. Scott, W.R. Reflections on a half-century of organizational sociology. Annu. Rev. Sociol. 2004, 30, 1-21.

7. Lammers, J.C. The effect of competition on labor management in nonprofit organizations. Nonprof. Volunt. Sect. Quart. 1990, 19, 171-186.

8. Neal, R. The importance of the state: Political dimensions of a nonprofit network in Oaxaca, Mexico. Nonprof. Volunt. Sect. Quart. 2008, 37, 492-511.

9. Ostrower, F.; Stone, M.M. Moving governance research forward: A contingency-based framework and data application. Nonprof. Volunt. Sect. Quart. 2009, 39, 901-924.

10. Wicker, P.; Breuer, C. Scarcity of resources in German non-profit sport clubs. Sport Manag. Rev. 2011, 14, 188-201.

11. Koski, P. Organizational effectiveness of Finnish sports clubs. J. Sport Manag. 1995, 9, 85-95.

12. Stone, M.M.; Sandfort, J.R. Building a policy fields framework to inform research on nonprofit organizations. Nonprof. Volunt. Sect. Quart. 2009, 38, 1054-1075.

13. Bryk, A.S.; Raudenbush, S.W. Hierarchical Linear Models; Sage Publications: Newbury Park, CA, USA, 1992.

14. Rotolo, T.; Wilson, J. State-level differences in volunteerism in the United States: Research based on demographic, institutional, and cultural macrolevel theories. Nonprof. Volunt. Sect. Quart. 2012, 41, 452-473.

15. Scott, W.R. Organizations. Rational, Natural, and Open Systems, 5th ed.; Prentice Hall: Upper Saddle River, NJ, USA, 2003. 
16. Pfeffer, J.; Salancik, G.R. The External Control of Organizations: A Resource Dependence Perspective; Harper and Row: New York, NY, USA, 1978.

17. Cadena-Roa, J.; Luna, M.; Puga, C. Associational performance: The influence of cohesion, decision-making, and the environment. Voluntas 2012, 23, 993-1013.

18. Oliver, C. Determinants of interorganizational relationships: integration and future directions. Acad. Manag. Rev. 1990, 15, 241-265.

19. Whetten, D.A.; Leung, T.K. The instrumental values of interorganizational relations: Antecedents and consequences of linkage formation. Acad. Manag. J. 1979, 22, 325-344.

20. Hillman, A.J.; Withers, M.C.; Collins, B.J. Resource dependence theory: A review. J. Manag. 2009, 35, 1404-1427.

21. Nienhueser, W. Resource dependence theory-How well does it explain behavior of organizations? Manag. Rev. 2008, 19, 9-32.

22. Moulton, S.; Eckerd, A. Preserving the publicness of the nonprofit sector: Resources, roles, and public values. Nonprof. Volunt. Sect. Quart. 2012, 41, 656-685.

23. Verschuere, B.; de Corte, J. The impact of public resource dependence on the autonomy of NPOs in their strategic decision making. Nonprof. Volunt. Sect. Quart. 2014, 43, 293-313.

24. Vos, S.; Breesch, D.; Késenne, S.; van Hoecke, J.; Vanreusel, B.; Scheerder, J. Governmental subsidies and coercive isomorphism: Evidence from sports clubs and their resource dependencies. Eur. J. Sport Soc. 2011, 8, 257-280.

25. Hetling, A.; Botein, H. Positive and negative effects of external influences on program design. Nonprofit Manag. Lead. 2010, 21, 177-194.

26. Mulroy, E.A. Community as a factor in implementing interorganizational partnerships. Nonprofit Manag. Lead. 2003, 14, 47-66.

27. Wicker, P.; Breuer, C. Understanding the importance of organizational resources to explain organizational problems: Evidence from non-profit sport clubs in Germany. Voluntas 2013, 24, 461-484.

28. Breuer, C.; Wicker, P. Analysis of the Situation of Sports Clubs in Germany; Sports Development Report 2009/2010; Abbreviated Version; Sportverlag Strauß: Cologne, Germany, 2011.

29. Misener, K.; Harman, A.; Doherty, A. Understanding the local sports council as a mechanism for community sport development. Manag. Leis. 2013, 18, 300-315.

30. Wagner, B. Budgetsanierung auf Kosten der Kultur? [Budget Improvement at the Expense of Culture?] Available online: http://kulturrisse.at/ausgaben/022010/kosmopolitiken/budgetsanierung -auf-kosten-der-kultur (accessed on 11 December 2013).

31. Schlenk, C.T. Der große Schuldengraben [The Big Debt]. Available online: http://www.zeit.de/wirtschaft/2013-09/schulden-statistik-kommunen-oberhausen (accessed on 11 December 2013).

32. Mackintosh, E. Report: Income Inequality Rising in Most Developed Countries. Available online: http://www.washingtonpost.com/blogs/worldviews/wp/2013/05/16/report-income-inequality-risingin-most-developed-countries/ (accessed on 21 May 2013).

33. Oechsner, T. Jeder vierte Beschäftigte erhält nur Niedriglohn [Every fourth employee only earns a low wage]. Available online: http://www.sueddeutsche.de/wirtschaft/2.220/studie-entfacht-neue- 
gerechtigkeitsdebatte-jeder-vierte-beschaeftigte-erhaelt-nur-niedriglohn-1.1308326 (accessed on 21 May 2013).

34. Andreff, W. Voluntary work in sport. In Handbook on the Economics of Sport; Andreff, W., Szymanski, S., Eds.; Edward Elgar: Cheltenham, UK, 2006; pp. 219-224.

35. Salamon, L.M.; Sokolowski, S.W.; Haddock, M.A. Measuring the economic value of volunteer work globally: Concepts, estimates, and a roadmap to the future. Ann. Public Coop. Econ. 2011, 82, 217-252.

36. Burgham, M.; Downward, P. Why volunteer, time to volunteer? A case study from swimming. Manag. Leis. 2005, 10, 79-93.

37. Schlesinger, T.; Nagel, S. Who will volunteer? Analysing individual and structural factors of volunteering in Swiss sports clubs. Eur. J. Sport Sci. 2013, 13, 707-715.

38. Freeman, R.B. Working for nothing: The supply of volunteer labor. J. Labor Econ. 1997, 15, S140-S166.

39. Federal and Regional Statistical Offices, Eds. Statistik lokal. Daten für die Gemeinden, kreisfreien Städte und Kreise Deutschlands [Local Statistics. Data of the Communities, Country Boroughs and Districts in Germany]; Landesamt für Datenverarbeitung und Statistik Nordrhein-Westfalen: Düsseldorf, Germany, 2008.

40. Tabachnick, B.G.; Fidell, L.S. Using Multivariate Statistics; Allyn \& Bacon: Boston, MA, USA, 2007.

41. Hox, J.J. Multilevel Analysis; Lawrence Erlbaum Associates: Mahwah, NJ, USA, 2002.

42. Snijders, T.A.B.; Bosker, R. Multilevel Analysis: An Introduction to Basic and Advanced Modeling; Sage: London, UK, 1999.

43. Todd, S.Y.; Crook, T.R.; Barilla, A.G. Hierarchical linear modeling of multilevel data. J. Sport Manag. 2005, 19, 387-403.

44. Wittenberg, R.; Cramer, H. Computergestützte Datenanalyse [Computer Assisted Data Analysis], 2nd ed.; Lucius \& Lucius: Stuttgart, Germany, 1998.

45. Bortz, J. Statistik für Human- und Sozialwissenschaftler [Statistics for the Human and Social Sciences], 6th ed.; Springer: Heidelberg, Germany, 2005.

46. White, H. A heteroskedastic-consistent covariance matrix estimator and a direct test for heteroskedasticity. Econometrica 1980, 48, 817-838.

47. Raudenbush, S.; Bryk, A.; Cheong, Y.; Congdon, R.; du Toit, M. HLM 6: Hierarchical Linear and Nonlinear Modeling; Scientific Software International, Inc.: Lincolnwood, IL, USA, 2004.

48. Wicker, P.; Breuer, C.; Lamprecht, M.; Fischer, A. Does club size matter? An examination of economies of scale, economies of scope, and organizational problems. J. Sport Manag. 2014, 28, 266-280.

49. Nagel, M. Die soziale Zusammensetzung der Sportvereinsmitglieder. In Integrationsleistungen von Sportvereinen als Freiwilligenorganisationen [Integration Achievements of Sport Clubs as Voluntary Organisations]; Baur, J., Braun, S., Eds.; Meyer \& Meyer: Aachen, Germany, 2003; pp. 409-448.

50. Christakis, N.A.; Fowler, J.H. Social contagion theory: Examining dynamic social networks and human behavior. Stat. Med. 2013, 32, 556-577. 
51. Coates, D.; Wicker, P.; Feiler, S.; Breuer, C. A bivariate probit examination of financial and volunteer problems of non-profit sport clubs. Int. J. Sport Financ. 2014, 9, 130-148.

52. Yeh, C.M.; Taylor, T. Issues of governance in sport organisations: A question of board size, structure and roles. World Leis. J. 2008, 50, 33-45.

53. Schäfers, M. Überschuldete Kommunen: Die Krise vor der Haustür [Overindebted Communities: The Crisis in Front of the Entry Door]. Available online: http://www.faz.net/aktuell/wirtschaft/ ueberschuldete-kommunen-die-krise-vor-der-haustuer-11619334.html (accessed on 13 January 2015).

(C) 2015 by the authors; licensee MDPI, Basel, Switzerland. This article is an open access article distributed under the terms and conditions of the Creative Commons Attribution license (http://creativecommons.org/licenses/by/4.0/). 